\title{
NUCLEOTIDE SEQUENCE OF SN-07 CHROMOPHORE BINDING SITE
}

\author{
Ken-ichi Kimura, Tomonori Morinaga, Nobuo Miyata and Gosei Kawanishi \\ Research Institute of Life Science, Snow Brand Milk Products Co., Ltd., \\ Ishibashi-machi, Shimotsuga-gun, Tochigi 329-05, Japan
}

(Received for publication May 31, 1989)

\begin{abstract}
DNase I footprinting was used to investigate binding sites for SN-07 chromophore on DNA fragments prepared from pBR322. Six sites were protected on about 150 base pair DNA fragments by $\mathrm{SN}-07$ chromophore, but not by related anthracycline antibiotics from DNase I digestion. All the protected sites contained the dinucleotide sequence $5^{\prime}-\mathrm{GC}-3^{\prime}$, but no other regularities could be discerned. A drug-induced conformational change of DNA was suggested by enhancement of DNase I sensitivity between the protected sites. These results support covalent interaction of the carbinolamine function of SN-07 chromophore to 2-amino group of guanine residues.
\end{abstract}

$\mathrm{SN}-07$ chromophore (barminomycin I) is an anthracycline antibiotic. It is atypical of this group in that it contains an eight-membered ring with the carbinolamine structure ${ }^{1 \sim 4)}$ (Fig. 1). The carbinolamine of $\mathrm{SN}-07$ chromophore is similar to those found in the covalent binding antibiotics such as pyrrolo $(1,4)$ benzodiazepine antibiotics (e.g., anthramycin, tomaymycin, sibiromycin and neothramy$(\mathrm{in})^{5 \sim 9)}$, saframycins ${ }^{10)}$ and naphthyridinomycin ${ }^{11)}$. SN-07 chromophore binds covalently to the DNA containing guanine and is intercalated into the DNA not containing guanine ${ }^{12,13)}$. Based on our results of restriction enzyme digestion of SN-07 chromophore- $\lambda$ DNA complex, we predicted that SN-07 chromophore preferentially binds to $5^{\prime}-\mathrm{GC}-3^{\prime}$ sequence ${ }^{13)}$.

DNase I footprinting analysis has been employed to investigate DNA binding characteristics of intercalative anthracycline antibiotics such as daunomycin and nogalamycin. Daunomycin did not show a clear pattern of protection because it easily dissociated from $\mathrm{DNA}^{14)}$. Recently, it was shown that the binding site for daunomycin contained adjacent $G C$ base pairs on binding at $4{ }^{\circ} \mathrm{C}^{15}$. Nogalamycin interacted

Fig. 1. Structure of $\mathrm{SN}-07$ chromophore (carbinolamine type).

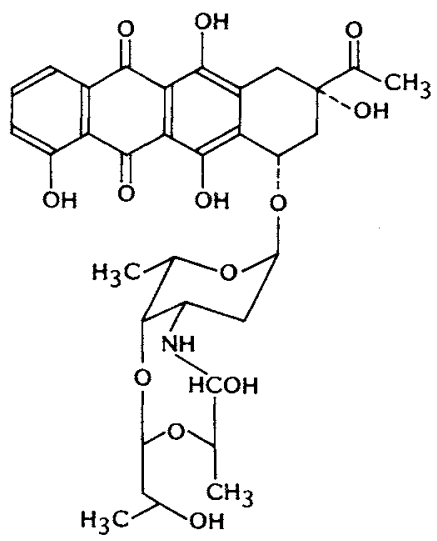
with DNA with a low sequence specificity ${ }^{14,16)}$. On the other hand, pyrrolo( 1,4$)$ benzodiazepine antitumor antibiotics that bound covalently to the 2-amino group of guanine showed a sequenceselective binding ability. The most preferred binding sequence for these drugs was $5^{\prime}-\mathrm{PuGPu}-3^{\prime}$ and the least was $5^{\prime}$-PyGPy- $3^{\prime 17}$.

The experiments described in this paper confirmed that an anthracycline antibiotic SN-07 chromophore bound to DNA in a sequence-selective fashion and the preferred sequence was $5^{\prime}-\mathrm{GC}-3^{\prime}$. In our knowledge, SN-07 chromophore was the first anthracycline antibiotic which bound to DNA covalently in a sequence-selective manner. 


\section{Materials and Methods}

Antibiotics, Enzymes and Chemicals

SN-07 chromophore was purified as described previously ${ }^{1}$. Carminomycin III and the reduction product were obtained by reacting $\mathrm{SN}-07$ chromophore with sodium cyanoborohydride ${ }^{2}$. Solution of each antibiotic was prepared by diluting the stock solution stored in methanol $(1 \mathrm{mg} / \mathrm{ml})$ at $-20^{\circ} \mathrm{C}$. T4 polynucleotide kinase was purchased from Boehringer Mannheim (Germany) and deoxyribonuclease I (DNase I) was purchased from Sigma Chemical Company (St. Louis, U.S.A.). Bacterial alkaline phosphatase, restriction enzymes and pBR322 were purchased from Takara Shuzo Co., Ltd. (Kyoto, Japan). All chemicals used were reagent grade. Chemicals for polyacrylamide gel were electrophoretic grade. $\left[\gamma-{ }^{32} \mathrm{P}\right] \mathrm{ATP}(>5,000 \mathrm{Ci} / \mathrm{mmol})$ was purchased from Amersham.

\section{DNA Substrates}

The Hind III - Hae III (position 30 174, 145 base-pairs (bp)) and Eco R V-Hind III (position 187 $34^{\dagger}$, $154 \mathrm{bp}$ ) fragments from plasmid pBR322 were used (Fig. 2). The minus (-) strand probe was prepared by cutting pBR322 DNA first with Hind III and the terminal $5^{\prime}$ phosphates were removed with bacterial alkaline phosphatase. The DNA was labeled with $\left[\gamma_{-}{ }^{32} \mathrm{P}\right] \mathrm{ATP}$ using T4 polynucleotide kinase and purified by Sephadex G-50 column chromatography. The ${ }^{32} \mathrm{P}$-labeled DNA fragment was cut by Hae III and the Hind III-Hae III fragment of 145 bp long (Fig. 2) was separated by $8 \%$ polyacrylamide gel electrophoresis. The fragment was extracted from the gel with elution buffer $\left(4 \times 10^{7} \mathrm{cpm} / \mu \mathrm{g}\right)$. The same procedure was employed for labeling plus (+) strand of pBR322 DNA except that pBR322 DNA was cut first by $E c o$ R $\mathrm{V}$ instead of Hind III. Specific activity of EcoR V-Hind III DNA fragment of 154 bp (Fig. 2) was $3 \times 10^{7} \mathrm{cpm} / \mu \mathrm{g}$.

\section{DNase I Footprinting}

SN-07 chromophore was mixed with one of the ${ }^{32}$ P-labeled DNA fragment in TE buffer $(10 \mathrm{~mm}$ Tris-HCl, $\mathrm{pH} 8.0,1 \mathrm{~mm}$ EDTA) according to the method described previously ${ }^{12)}$. The mixture was incubated for 2 days at room temperature and $1 \mu \mathrm{g}$ of poly $(\mathrm{dI})$-poly $(\mathrm{dC})$ was added to the mixture. SN-07 chromophore-DNA complex thus made was then digested with DNase I in $25 \mu$ l of DNase I buffer (10 mM Tris- $\mathrm{HCl}$, pH 7.5, $50 \mathrm{~mm} \mathrm{NaCl}, 1 \mathrm{~mm}$ DTT, $0.5 \mathrm{~mm}$ EDTA, $2.5 \mathrm{~mm} \mathrm{MgCl}_{2}, 5 \%$ glycerol). The final DNase I concentration was $0.4 \mu \mathrm{g} / \mathrm{ml}$ and the solution was incubated for 1 minute at room temperature. The reaction mixture was dried under vacuum after adding $1 \mu \mathrm{l}$ of $0.5 \mathrm{~m}$ EDTA. The DNA was resuspended

Fig. 2. Sequence and numbering scheme for the pBR322 DNA fragment.
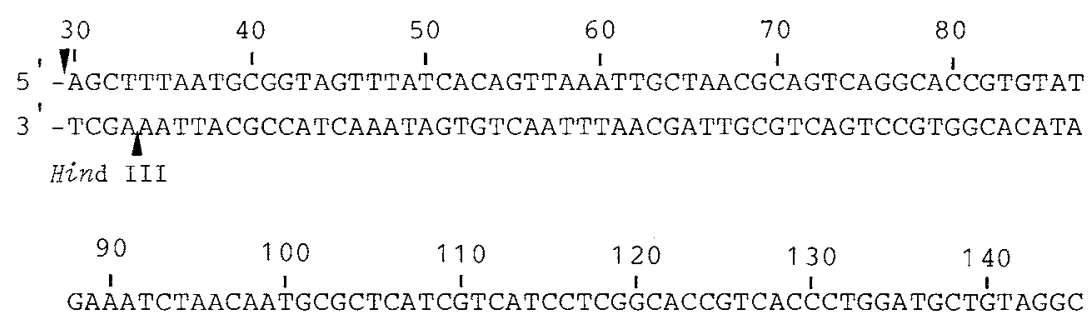

CTTTAGATTGTTACGCGAGTAGCAGTAGGAGCCGTGGCAGTGGGACCTACGACATCCG

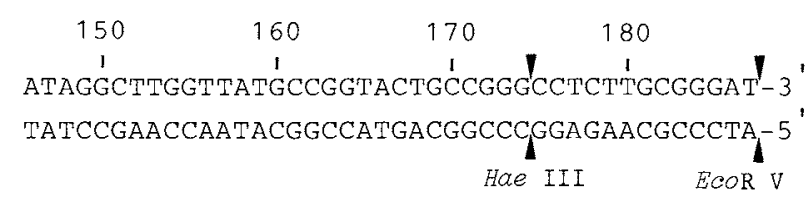

† The nucleotides are numbered in a clockwise direction from the single $E c o$ R I site. Nucleotide 1 is the first tymidine residue in the $E c o$ R I site. 
in $80 \%$ formamide - $10 \mathrm{~mm} \mathrm{NaOH}-1 \mathrm{~mm}$ EDTA-0.1\% xylene cyanol $-0.1 \%$ bromophenol blue and incubated at $90^{\circ} \mathrm{C}$ for 5 minutes prior to gel electrophoresis.

Gel Electrophoresis

The digestion products of Hind III-Hae III and EcoR V-Hind III fragments were analyzed on a 0.4-mm thick $8 \%(\mathrm{w} / \mathrm{w})$ polyacrylamide gel containing $7 \mathrm{M}$ urea in Tris-borate-EDTA buffer (pH 8.3). After electrophoresis at $1,700 \mathrm{~V}$ for 3 hours, the gel was dried and subjected to autoradiography at $-80^{\circ} \mathrm{C}$ with an intensifying screen. Bands in the digestion pattern were assigned by using formic acid-piperidine markers specific for guanine and adenine ${ }^{18)}$.

\section{Results}

Footprinting patterns for the $145 \mathrm{bp}$ Hind III-Hae III DNA fragment in the presence and absence of SN-07 chromophore are displayed in Fig. 3. It was immediately apparent that the cleavage pattern in the presence of SN-07 chromophore was substantially different from that of the DNA alone. At molar ratios of SN-07 chromophore to DNA fragment of 0.5:1 (lanes 3 and 4 in Fig. 3) and 50:1 (lanes 5 and 6), six sites near positions 68 (site A), 79 (site B), 105 (site C), 122 (site D), 141 (site E) and 163 (site F) from EcoR I site were protected with $\mathrm{SN}-07$

Fig. 3. DNase I digestion patterns for the $145 \mathrm{bp}$ pBR322 DNA (labeled at the $5^{\prime}$ end of the upper strand) in the presence of $\mathrm{SN}-07$ chromophore.

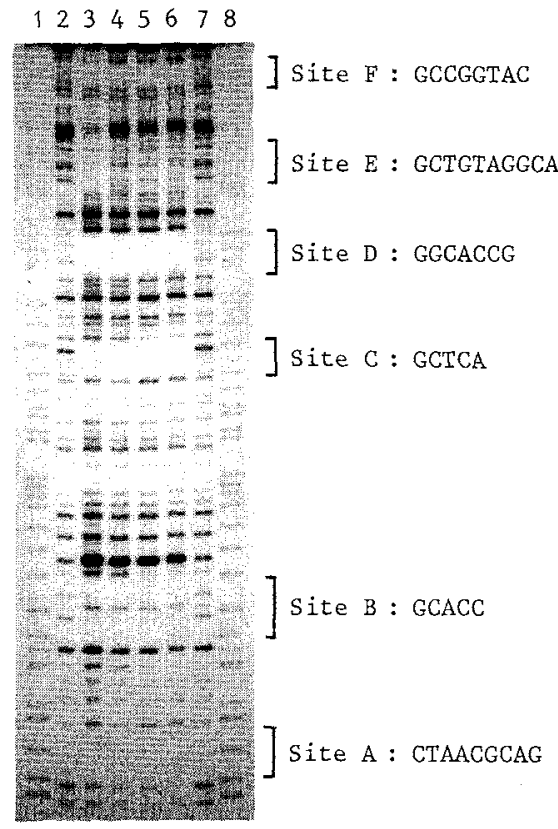

The digestion was performed as described under the Materials and Methods.

Lanes 1 and 8: Maxam-Gilbert $\mathrm{A}+\mathrm{G}$ reactions. Lanes 2 and 7: Control digestions without SN-07 chromophore. Lanes 3 and 4: SN-07 chromophoreDNA $(0.5: 1)$. Lanes 5 and $6: \mathrm{SN}-07$ chromophoreDNA $(50: 1)$.
Fig. 4. DNase I digestion patterns for the $145 \mathrm{bp}$ pBR322 DNA (labeled at the $5^{\prime}$ end of the upper strand) in the presence of SN-07 chromophore and related compounds.

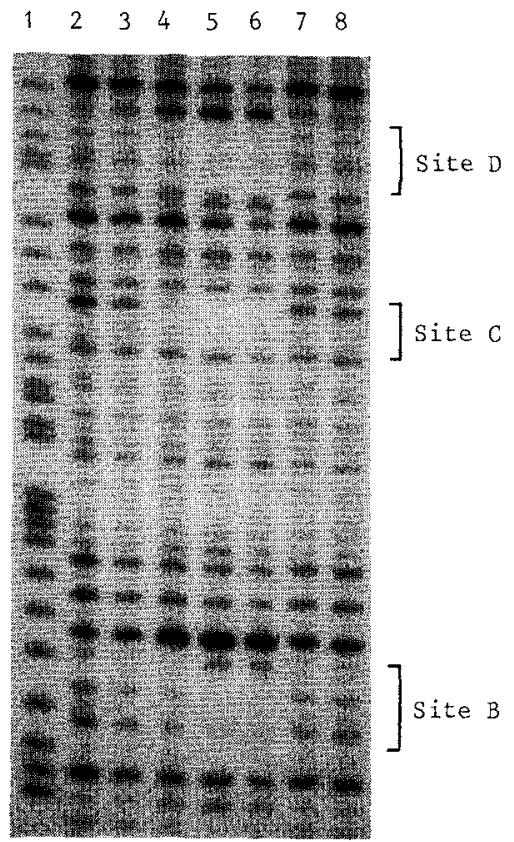

The digestion was performed as described under the Materials and Methods.

Lane 1: Maxam-Gilbert $A+G$ reaction. Lane 2: control digestion without SN-07 chromophore. Lane 3: SN-07 chromophore-DNA (0.004:1). Lane 4: SN-07 chromophore-DNA $(0.02: 1)$. Lane 5: SN-07 chromophore-DNA $(0.1: 1)$. Lane 6: SN-07 chromophore-DNA $(0.5: 1)$. Lane 7 : carminomycin III - DNA $(0.5: 1)$. Lane 8 : reduction product -DNA $(0.5: 1)$. 
Fig. 5. DNase I digestion patterns for the $154 \mathrm{bp}$ pBR322 DNA (labeled at the 5 ' end of the lower strand) in the presence of SN-07 chromophore and carminomycin III.

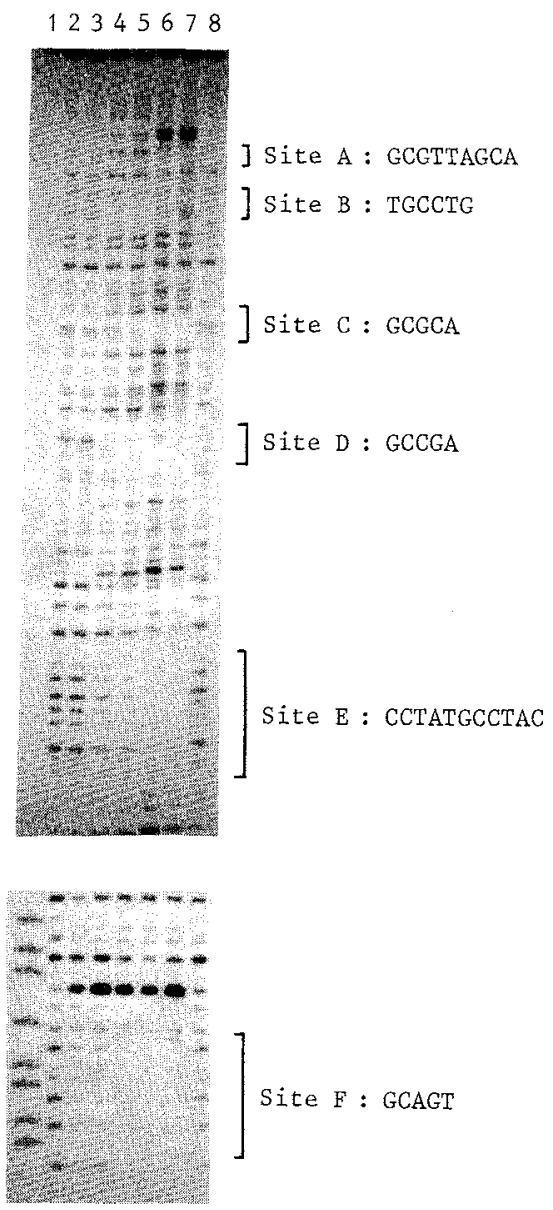

The digestion was performed as described under the Materials and Methods.

Lane 1: Maxam-Gilbert $A+G$ reaction. Lane 2: control digestion without SN-07 chromophore. Lane 3: SN-07 chromophore-DNA $(0.004: 1)$. Lane 4: SN-07 chromophore - DNA (0.02:1). Lane 5: SN-07 chromophore-DNA $(0.1: 1)$. Lane 6: SN-07 chromophore-DNA $(0.5: 1)$. Lane 7: SN-07 chromophore - DNA (50:1). Lane 8: carminomycin III - DNA $(0.5: 1)$. chromophore. The protected regions were five to ten base pairs long. An increased DNase I sensitivity was observed at the regions adjacent to the protected sites (Fig. 3).

The pattern of cleavage varies with the antibiotic concentration (Fig. 4). The protection was observed at the molar ratio of $\mathrm{SN}-07$ chromophore to DNA of $0.02: 1$ (lane 4 in Fig. 4). The inhibition of restriction enzyme reaction was also observed at the same SN-07 chromophore to DNA ratio ${ }^{13)}$.

On the other hand, related anthracycline antibiotic, carminomycin III and the reduction product of $\mathrm{SN}-07$ chromophore ${ }^{2)}$ that did not contain a carbinolamine structure, had almost no effect on the cleavage pattern in the above conditions (lanes 7 and 8 in Fig. 4).

A typical DNase I footprinting pattern for the $154 \mathrm{bp} E c o \mathrm{R}$ V-Hind III DNA fragment is shown in Fig. 5. At molar ratio of $\mathrm{SN}-07$ chromophore to DNA fragment of 0.5:1 (lane 6 in Fig. 5), six sites near positions 66 (site A), 76 (site B), 102 (site C), 119 (site D), 145 (site E) and 168 (site F) from EcoR I site were protected with $\mathrm{SN}-07$ chromophore. The protected region at each site was five to eleven base pairs long. Enhanced sensitivity to DNase I was observed at the regions adjacent to the binding sites (Fig. 5).

The results described above are summarized in Fig. 6. Almost all the $5^{\prime}-\mathrm{GC}-3^{\prime}$ sequences in the fragment were located in the DNase I resistant sites. In some sites (sites $\mathrm{A}, \mathrm{B}, \mathrm{C}$ and $\mathrm{D}$ ), the block staggered across the two strands by about two to three bases toward the $3^{\prime}$ end, as previously observed for DNase I footprinting with other antibiotics ${ }^{19}$.

\section{Discussion}

Footprinting is a technique that has been developed to identify the precise binding sites for ligands on DNA fragments of defined sequence. Sites to which the antibiotic is bound are protected from enzymatic (or chemical) cleavage and are visualized at a single band resolution as gaps in the autoradiogram of a denaturing polyacrylamide gel $^{20)}$.

Biochemical target for many antitumor antibiotics are DNA. They recognize DNA sequence with varying degrees of specificity. Among them are several antibiotics such as actinomycin which binds to 
Fig. 6. Summary of footprinting results for SN-07 chromophore.

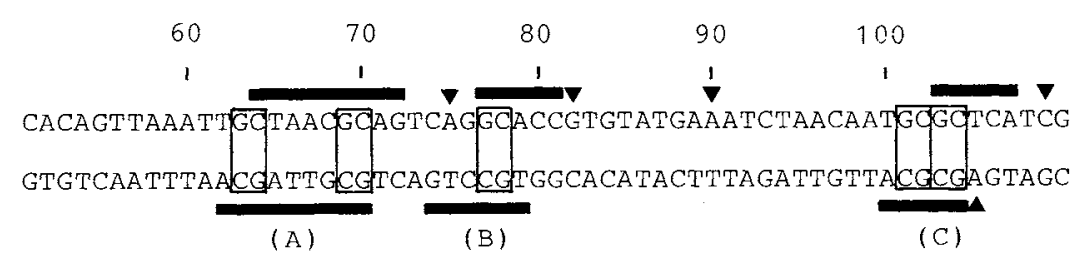

(A)

(B)

(C)

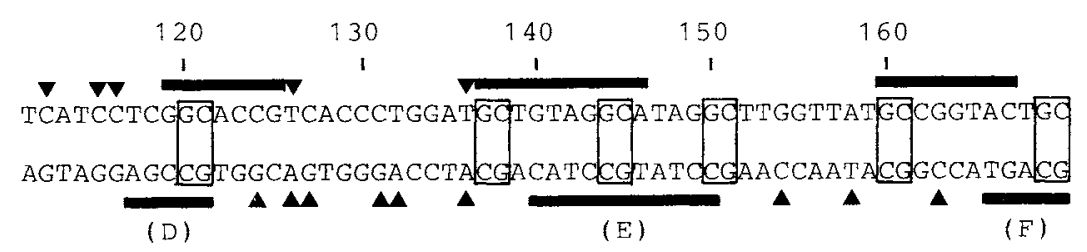

Bars indicate protected regions while triangles show positions of enhanced DNase I sensitivity. The upper sequence represents the 'Watson' $(-)$ strand and the lower sequence represents the 'Crick' $(+)$ strand. These maps were complied from visual inspection of numerous gels and may be considered as a set of averaged values.

sequence $5^{\prime}-\mathrm{GC}-3^{\prime 21,22)}$, echinomycin to $5^{\prime}-\mathrm{CG}-3^{\prime 19,23)}$, mithramycin to $5^{\prime}-\mathrm{GG}-3^{\prime 24}{ }^{25)}$, pyrrolo $(1,4)$ benzodiazepine antibiotics to $5^{\prime}-\mathrm{PuGPu}-3^{\prime 17)}$, and distamycin to AT rich regions ${ }^{21)}$. On the other hand, sequence-selectivity of the intercalative anthracycline antibiotic daunomycin was shown only under the restricted conditions ${ }^{15}$. Nogalamycin binds to preferential regions of mixed sequence containing purines and pyrimidines ${ }^{16)}$.

SN-07 chromophore is an anthracycline antibiotic. But it is unique because it has two binding sites for DNA, namely, carminomycinone(intercalation) and carbinolamine(covalent binding) structures (Fig. 1). We have shown by restriction enzyme digestion studies that $\mathrm{SN}-07$ chromophore has a preferred sequence selectivity for $5^{\prime}-\mathrm{GC}-3^{\prime}$. The sequence selectivity was presumably due to the carbinolamine function of $\mathrm{SN}-07$ chromophore which differed from the related anthracycline antibiotics ${ }^{12,13)}$.

The results presented in this paper show that $\mathrm{SN}-07$ chromophore did induce considerable changes in the susceptibility of particular nucleotide sequences to the attack by DNase I. Observed DNase I sensitive sites (Fig. 6) presumably resulted from conformational changes in the DNA induced by the binding of the ligand ${ }^{16,19,21}$. Similar enhancement of DNase I cleavage has previously been observed with other sequence selective ligands ${ }^{24,26)}$. In the $\mathrm{E}$ and $\mathrm{F}$ regions, the block staggered across the two strands toward the $5^{\prime}$ end differing from $\mathrm{A}, \mathrm{B}, \mathrm{C}$ and $\mathrm{D}$ regions. This might depend on the conformational changes of $\mathrm{E}$ and $F$ resistance regions.

DNase I footprinting patterns produced by SN-07 chromophore bound on pBR322 DNA fragment revealed that all six DNase I resistance resions contained $5^{\prime}-\mathrm{GC}-3^{\prime}$ sequence. Some site protected with $\mathrm{SN}-07$ chromophore was longer than those protected by other antibiotics. More than 2 molecules of SN-07 chromophore might bind to the $\mathrm{A}, \mathrm{E}$ and $\mathrm{F}$ regions.

These results were entirely consistent with our previous results and the hypothetical binding model of SN-07 chromophore to DNA, that is, SN-07 chromophore covalently bind to 2-amino group of guanine ${ }^{12)}$. SN-07 chromophore was the first anthracycline antibiotic that bind to DNA covalently in a sequence-selective manner by carbinolamine function.

Acknowledgments

We are grateful to Prof. S. Mizuno, Tohoku University, Sendai, and Dr. A. YUki, Research Institute of Life Science, Snow Brand Milk Products Co., Ltd., for their helpful advice on this study. 


\section{References}

1) Kimura, K.; S. Nakayama, T. Koyama, S. Shimada, N. Kawaguchi, N. Miyata, Y. Takeshita \& G. Kawanishi: SN-07 chromophore: An anthracycline antibiotic from the macromolecular antibiotic SN-07. J. Antibiotics 40: $1353 \sim 1355,1987$

2) Kimura, K.; S. Nakayama, N. Miyata, Y. Takeshita \& G. Kawanishi: The structure of SN-07 chromophore. J. Antibiotics 41: $411 \sim 414,1988$

3) Kimura, K.; S. Nakayama, N. Miyata \& G. Kawanishi: Structural alteration of SN-07 chromophore. J. Antibiotics 42: $127 \sim 131,1989$

4) Uchida, T.; M. Imoto, Y. Takahashi, A. Odagawa, T. Sawa, K. Tatsuta, H. Naganawa, M. Hamada, T. TAKeUChi \& H. UmezAWa: New potent anthracyclines, barminomycins I and II. J. Antibiotics 41: 404 408, 1988

5) Hurley, L. H.: Pyrrolo(1,4)benzodiazepine antitumor antibiotics. Comparative aspects of anthramycin, tomaymycin and sibiromycin. J. Antibiotics 30: 349 370, 1977

6) Hurley, L. H. \& R. Petrusek: Proposed structure of the anthramycin-DNA adduct. Nature 282: 529 531, 1979

7) Petrusek, R. L.; G. L. Anderson, T. F. Garner, Q. L. Fannin, D. J. Kaplan, S. G. Zimmer \& L. H. Hurley: Pyrrolo[1,4]benzodiazepine antibiotics. Proposed structures and characteristics of the in vitro deoxyribonucleic acid adducts of anthramycin, tomaymycin, sibiromycin, and neothramycins A and B. Biochemistry 20: 1111 1119, 1981

8) Hurley, L. H.; C. S. Allen, J. M. Feola \& W. C. Lubawy: In vitro and in vivo stability of anthramycin-DNA conjugate and its potential application as an anthramycin prodrug. Cancer Res. 39: $3134 \sim 3140,1979$

9) Maruyama, I. N.; N. Tanaka, S. Kondo \& H. Umezawa: Structure of a neothramycin-2'-deoxyguanosine adduct. Biochem. Biophys. Res. Commun. 98: 970 975, 1981

10) Lown, J. W.; A. V. JoshuA \& J. S. LeE: Molecular mechanisms of binding and single-strand scission of deoxyribonucleic acid by the antitumor antibiotics saframycins A and C. Biochemistry 21: 419 428, 1982

11) ZmiJeWSKI, M. J., Jr.; K. Miller-Hatch \& M. MikolaJCZaK: The in vitro interaction of naphthyridinomycin with deoxyribonucleic acids. Chem. Biol. Interact. 52: $361 \sim 375,1985$

12) Kimura, K.; H. Takahashi, S. Nakayama, N. Miyata \& G. Kawanishi: Reconstruction of the macromolecular antitumor antibiotic SN-07 from SN-07 chromophore and DNA. Agric. Biol. Chem. 53: 1797 1803, 1989

13) Kimura, K.; S. Nakayama, N. MiYata \& G. Kawanishi: Specific binding of SN-07 chromophore, an anthracycline antibiotic, to DNA. Agric. Biol. Chem. 53: 1805 1810, 1989

14) Fox, K. R.; C. BRASSETT \& M. J. WARING: Kinetics of dissociation of nogalamycin from DNA: comparison with other anthracycline antibiotics. Biochim. Biophys. Acta 840: $383 \sim 392,1985$

15) Chaires, J. B.; K. R. Fox, J. E. Herrera, M. Britt \& M. J. Waring: Site and sequence specificity of the daunomycin-DNA interaction. Biochemistry 26: 8227 8236, 1987

16) Fox, K. R. \& M. J. WARING: Nucleotide sequence binding preferences of nogalamycin investigated by DNase I footprinting. Biochemistry 25: 4349 4356, 1986

17) Hertzberg, R. P.; S. M. Hecht, V. L. Reynolds, I. J. Molineux \& L. H. Hurley: DNA sequence specificity of the pyrrolo[1,4]benzodiazepine antitumor antibiotics. Methidium propyl-EDTA-iron (II) footprinting analysis of DNA binding sites for anthramycin and related drugs. Biochemistry 25: $1249 \sim 1258,1986$

18) Maxam, A. M. \& W. Gilbert: A new method for sequencing DNA. Proc. Natl. Acad. Sci. U.S.A. $74: 560 \sim 564$, 1977

19) Low, C. M. L.; H. R. DREW \& M. J. WARING: Sequence-specific binding of echinomycin to DNA: evidence for conformational changes affecting flanking sequences. Nucleic Acids Res. 12: 4865 4879, 1984

20) Galas, D. J. \& A. Schmitz: DNAase footprinting: a simple method for the detection of protein-DNA binding specificity. Nucleic Acids Res. 5: 3157 3170, 1978

21) Fox, K. R. \& M. J. WARING: DNA structural variations produced by actinomycin and distamycin as revealed by DNAase I footprinting. Nucleic Acids Res. 12: 9271 9285, 1984

22) SOBELL, H. M. \& S. C. JAIN: Stereochemistry of actinomycin binding to DNA. II. Detailed molecular model of actinomycin - DNA complex and its implications. J. Mol. Biol. 68: 21 34, 1972

23) VAn Dyke, M. M. \& P. B. Dervan: Echinomycin binding sites on DNA. Science 225: 1122 1127, 1984

24) Fox, K. R. \& N. R. HowarTH: Investigations into the sequence-selective binding of mithramycin and related ligands to DNA. Nucleic Acids Res. 13: 8695 8714, 1985

25) BEHR, W.; K. HONIKEL \& G. HARTMANN: Interaction of the RNA polymerase inhibitor chromomycin with DNA. Eur. J. Biochem, 9: 82 92, 1969

26) LOW, C. M. L.; R. K. OLSEN \& M. J. WARING: Sequence preferences in the binding to DNA of triostin A and TANDEM as reported by DNase I footprinting. FEBS Lett. 176: 414 420, 1984 